\title{
Spray-drying optimization for red pitaya peel (Hylocereus polyrhizus).
}

\begin{abstract}
Optimization for the spray-drying of pitaya peel (Hylocereus polyrhizus) was carried out using the central composite design (CCD) of the response surface methodology to study the effect of inlet air temperature $\left(155-175{ }^{\circ} \mathrm{C}\right)$, outlet air temperature $\left(75-85{ }^{\circ} \mathrm{C}\right.$ ), and maltodextrin DE10 concentration $(8-22 \% \mathrm{w} / \mathrm{w})$ on the pitaya peel powder characteristics. Spray-dried pitaya peel powders had high betacyanin retention and low water activity and had desirable color, solubility, and hygroscopicity properties. Significant $(p<0.05)$ response surface models with high coefficients of determination values $(\mathrm{R} 2>0.85)$ ranging from 0.896 to 0.979 fitted for the experimental data were obtained. The linear term of maltodextrin concentration was found to be the most significant $(p<0.05)$ variable influencing the powder characteristics, and the outlet temperature had the least effect. The overall optimum region for the spray-drying of the desirable pitaya peel powder was predicted at a combined parameter of inlet air temperature at $165^{\circ} \mathrm{C}$, outlet air temperature at $80^{\circ} \mathrm{C}$, and maltodextrin DE10 at $15 \%(\mathrm{w} / \mathrm{w})$.
\end{abstract}

Keyword: Pitaya peel; Spray-dried; Optimization; Powder characteristics. 